\title{
Determination of Orobanche spp. distribution and occurrence in North Gondar, Ethiopia
}

\author{
Anteneh Ademe Mengistu ${ }^{*}$, Yohannes Ebabuye ${ }^{2}$, Getachew Tilahune ${ }^{3}$, Mesganaw Gelaye ${ }^{4}$ \\ ${ }^{1}$ Department of Plant Pathology, Gondar Agricultural Research Centre, Gondar, ETHIOPIA \\ ${ }^{2}$ Department of Plant Protection, Gondar Agricultural Research Centre, Gondar, ETHIOPIA \\ ${ }^{3}$ Department of Plant Breeder, Adet Agricultural Research Center, Adet, ETHIOPIA \\ ${ }^{4}$ Department of Plant Science, Gondar Agricultural Research Center, Gondar, ETHIOPIA \\ *Corresponding Contact: \\ Email: ad.antish@gmail.com
}

\begin{abstract}
The survey was done on major pulse crop growing districts with the objective of assessing the distribution and occurrence of Orobanche spp. in the highlands of North Gondar. Representative Farmer's fields from selected seven districts were assessed in every 5-10 $\mathrm{km}$ interval along the road ride to record the incidence, prevalence and severity of Orobanche spp. In all surveyed districts of N. Gondar Orobanche crenata was found with the highest prevalence and incidence of $85.71 \%$ and $10.71 \%$, respectively on fields covered with Linseed. Among districts, the highest prevalence of $66.67 \%$ was recorded on both Chilga and Gonder zuria districts. In addition to this, a maximum severity of 3 out of 6 (i.e. majority of host plants infected with two shoots) was recorded only on two fields out of all fields surveyed of the seven districts. During the survey, it was found that Xanthium strumarium was its wild host. Finally, awareness creation and establishment of quarantine system should be done to minimize the dissemination of parasitic weed seed to other areas within the administrative zone and the region. Likewise, different management options should be developed in the future not only to minimize the yield loss due to Orobanche crenata but also to manage its wild hosts like Xanthium strumarium.
\end{abstract}

Keywords: Orobanche crenata, Pulse crops, Xanthium strumarium

4/17/2017

Source of Support: Nil, No Conflict of Interest: Declared

This article is is licensed under a Creative Commons Attribution-NonCommercial 4.0 International License.

Attribution-NonCommercial (CC BY-NC) license lets others remix, tweak, and build upon work non-commercially, and

although the new works must also acknowledge \& be non-commercial.

\section{INTRODUCTION}

The genus Orobanche L. (broomrape) comprises some one hundred parasite species associated with various host plants and growing throughout the world (Kojic et al., 2001). Orobanche spp. have threatened legume crops since antiquity and affect the livelihood of many nations (Joel et al., 2007). Heavy Orobanche infestation does not only lead to a complete crop failure, but make field soils Orobanche-sick over a long period of time, preventing the reasonable production of legumes and vegetables in the infested fields for many years to come (Evidente et al., 2011).

Orobanche species are parasitic on a wide range of plant families (Asteracea, Fabaceae, Solanaceae, Apiaceae, Cucurbitaceae) (Linke et al., 1989; Suh et al., 2014). Yield losses range 
from 5 to $100 \%$ depending on the region and crop. In addition, a single broomrape plant can release more than 500,000 seeds, which are known to remain viable for decades in the soil. This provides the parasite with a great genetic adaptability to environmental changes, including host resistance, agronomical practices and herbicide treatments (Joel et al., 2007).

The growth of the parasite depends on water, mineral and organic compounds from the host. Due to the withdrawal of water, minerals and organic compounds by the parasites, the growth of the host is retarded, and crop yields are lowered or reduced to zero under conditions of severe infestation. Growth of Orobanche spp. shoots becomes very rapid during that period and it causes lack of carbohydrate in the host roots. Depending on environmental conditions, the underground phase of the life-cycle of $O$. crenata ranges from 30 to approximately 100 days. The life cycle from seed germination to seed production is about 3-5 months (Suh et al., 2014).

Orobanche species exert their greatest damage prior to their emergence; therefore, the majority of field loss may occur before diagnosis of infection. Annual food crop losses due to Orobanche spp. infestation was estimated at about $\$ 1.3$ to 2.6 billion (Ghannam et al., 2007). Orobanche species are distributed worldwide from temperate climates to semiarid tropics except for Orobanche crenata whose distribution is restricted to the Mediterranean regions, the Middle East and East Africa (Evidente et al., 2011).

Parasitic weed like Orobanche is one of the production constraints of food legume crops in the country and the distribution of this parasitic weed increases from time to time in Ethiopia. Thus, the survey was done with the aim of assessing the distribution and occurrence of Orobanche in the high lands of North Gondar zone.

\section{Material AND Methods}

Description of the study area: Field survey was conducted in the main cropping season of $2014 / 15$ on the major pulse growing areas of North Gondar. It is located $12.4500^{\circ} \mathrm{N}$ latitude and $37.0000^{\circ} \mathrm{E}$ longitude. North Gondar is bordered on the South by Lake Tana, West Gojjam, Agew Awi and the Benishangul-Gumuz Region, on the West by Sudan, on the North by the Tigray Region, on the East by Wag Himra and on the southeast by South Gondar. Pulse crops mainly grown at Debark, Dabat, Wogera, Gondar zuria, Taqusa and Chilga districts.

Survey of Orobanche spp. in North Gondar: Representative farmer's fields were assessed in every $5 \mathrm{~km}$ interval along the road ride to determine the distribution and occurrence of Orobanche. The incidence Orobanche were taken by classifying in to three categories: Low (less than 20\% infestation), Medium (20-50\% infestation) and high (more than 50\% infestation) and the severity was measured using a 0-6 scale (Kroschel, 2001).

Table 1: Severity scale used in assessment of Orobanche spp. distribution in North Gondar

\begin{tabular}{|c|l|l|}
\hline Rating scale & Infestation & Definition \\
\hline 0 & Not infested & No Orobanche emerged \\
\hline 1 & Very low & Very few Orobanche shoots in the whole field \\
\hline 2 & Low & Few Orobanche shoots in the whole field \\
\hline 3 & Moderate & Majority of the host plants infected with 2 shoots \\
\hline 4 & High & Host plants infected with more than 2 shoots \\
\hline 5 & Very high & $\begin{array}{l}\text { All host plants infected with more than 5 } \\
\text { shoots fields seemed to be an Orobanche field }\end{array}$ \\
\hline 6 & Host plant completely destroyed & Host plants dead, no yield \\
\hline
\end{tabular}




\section{RESULt AND Discussion}

The field survey covered major pulse producing districts in North Gondar administrative zone with an altitude ranging from 1838 to 3151 meter above sea level. In all surveyed areas, low to medium Orobanche spp. was recorded. The Orobanche spp. found in surveyed areas of North Gondar was Orobanche crenata and its prevalence varied with altitude across districts.

Crops with poor crop condition were severely infested with Orobanche crenata. The highest prevalence of Orobanche crenata was recorded around Chilga and Gondar zuria districts with an average altitude of 2071 and 2030 meter above sea level followed by Gondar town with an average altitude of 2086 meter above sea level (Fig 1). In agreement with this study, Gonzáles-Andújar et al. (2001) indicated that Orobanche crenata does not always show a uniform geographical distribution in the invaded areas.

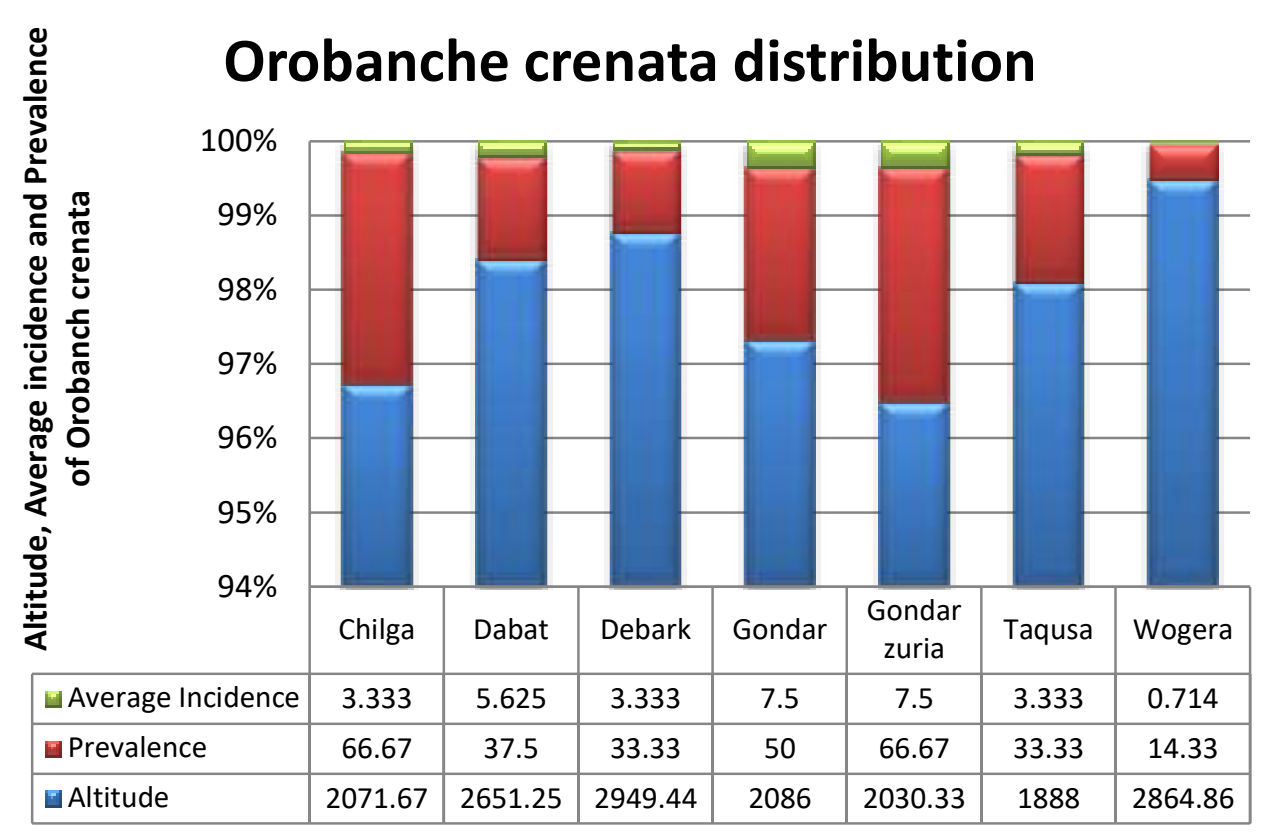

Fig 1: Prevalence and Incidence of Orobanche crenata at different altitude

Incidence of Orobanche crenata varies across surveyed districts. Out of the seven districts, four of them had low level of Orobanche crenata infestation. However, Medium level of infestation was recorded only on three fields covered with Field pea, Faba bean and Linseed crops at Gondar, Gondar zuriya and Dabat districts, respectively. The highest severity of Orobanche crenata, which was 3 out of 6, was recorded only on two fields covered with Field pea and Linseed at Gondar and Dabat districts.

Incidence and prevalence of Orobanche crenata varied with crop types (Fig 2). Fields covered with Linseed had highest incidence and prevalence of Orobanche crenata, 10.71\% and 85.71\%, respectively. In contrary, the least incidence of Orobanche crenata with wider distribution was recorded on fields covered with Faba bean (Fig 2). In addition to its association with Linseed, Faba bean and Field pea; Orobanche crenata were found by forming association with Xanthium strumarium weed in bare land and sorghum fields. In line with this, Orobanche crenata occurred across districts regardless of the crop production system, crop condition and crop type. 


\title{
Orobanche crenata with crop types
}

\author{
国 prevalence incidence
}

\subsection{1}

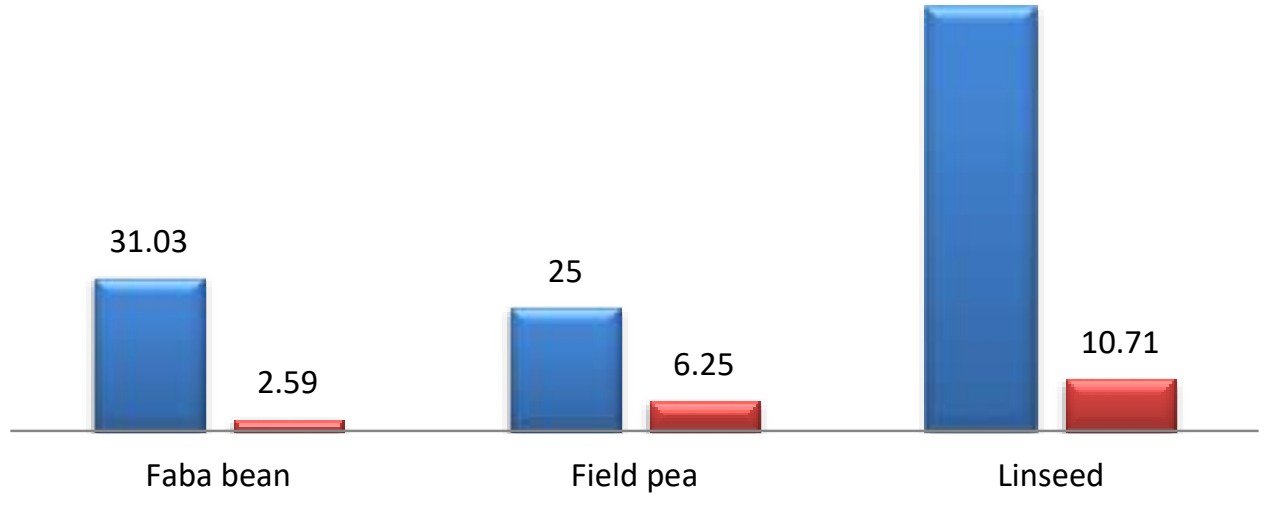

Fig 2: Prevalence and average incidence of Orobanche crenata with crop types

The variability in incidence and prevalence across surveyed districts either it might came from absence of Orobanche crenata seed in large amount in the soil or due to fluctuation in temperature. Temperature is one important abiotic factor that controls broomrape development. Soil temperature fluctuations during a warm wet period are required for the activation of germination hormones (Song et al., 2005).

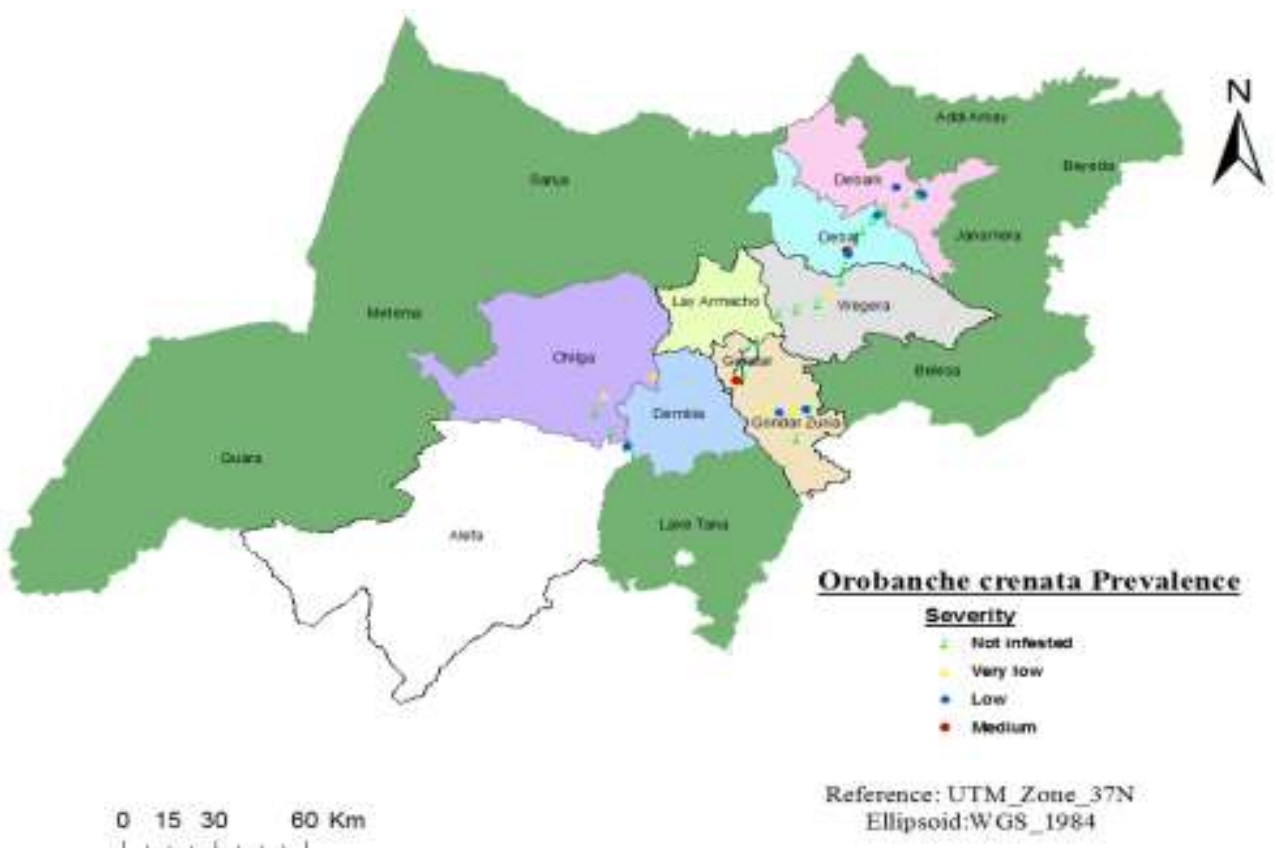

Fig 3: Map of districts assessed during the survey 
Orobanche crenata was only recorded with a prevalence of $44.44 \%$ on fields having light soil. Soil texture can also influence the vegetation structure (Dodd et al., 2002). Likewise, Soil texture could have impact on the parasitic weed virulence. The increased coarse sand content was positively associated with Orobanche attack intensity under greenhouse conditions (Miladinović et al., 2012) and Orobanche spp. generally occurs on sandy soils where nitrogen availability is poor (Dhanapal et al., 1996). We observed that some farmers didn't have a clue about the parasitic weed. Likewise, during the survey we observed that without drastic measures to stop the spread of Orobanche crenata, it will reach to the level in which production pulse crop will be difficult and the whole area is at high risk of full scale infestation. Therefore, awareness creation to prevent the weed problem gradual increment in the area and establishment of quarantine system should be done to prevent the dissemination of the parasitic weed seed from one are to the other. Finally, development of integrated management options should be the focus in the future not only to minimize the yield loss due to the parasitic weed but also to manage its wild host.

\section{ACKNOWLEDGEMENT}

The authors thank Dr. Sied kemal, Dr. Negussie Tadess and EMBRAPA project for their financial and technical assistance.

\section{REFERENCE}

Dhanapal GN, Struik PC, Udayakumar M, Timmermans PCJM (1996). Management of broomrape (Orobanchespp.) - A review. Journal of Agronomy and Crop Science 175: 335-359.

Dodd MB, Lauenroth WK, Burke IC, Chapman PL (2002). Associations between vegetation patterns and soil texture in the short grass steppe. Plan Ecology 158: 127-137.

Evidente E, Abouzeid MA, Andolfi A, Cimmino A (2011). Recent Achievements in the Bio-control of Orobanche Infesting Important Crops in the Mediterranean Basin. Journal of Agricultural Science and Technology, 1: 461-483.

Ghannam I, Barakat R, Al-Masri M (2007). Biological control of Egyptian broomrape (Orobanche aegyptiaca) using Fusarium spp., Phytopathologia Mediterranea 46: 177-184.

González-Andújar JL, Martínez-Cob A, López-Granados F, García-Torres L (2001). Spatial distribution and mapping of crenate broomrape infestations in continuous broad bean cropping. Weed Science 49: 773-779.

Joel DM, Hershenhorn Y, Eizenberg H, Aly R, Ejeta G, Rich PJ, Ransom JK, Sauerborn J, Rubiales D (2007). Biology and management of weedy root parasites. In: Janick, J. (Ed.), Horticultural Reviews, vol. 33. Wiley, New York, pp. 267-350.

Kojic M, Masirevic S, Jovanovic D (2001). Distribution and Biodiversity of Broomrape (Orobanche L.) Worldwide and In Serbia. HELIA, 24:73-92.

Kroschel J (2001). A technical manual for parasitic weed research and extension.Kluwer Acadamic Publisher, Dordrecht.

Miladinović D, Cantamutto M, Vasin J, Dedić B, Alvarez D, Poverene M (2012). Exploring environmental determinants of the geographic distribution of Broomrape (Orobanche Cumana wallr.) HELIA, 35, Nr. 56, p.p. 79-88

Parker C (1991). Protection of crops against parasitic weeds. Crop Prot. 10, 6-22.

Song WJ, Zhou WJ, Jin ZL, Cao DD, Joel DM, Takeuchi Y, Yoneyama K (2005). Germination response of Orobanche seeds subjected to conditioning temperature, water potential and growth regulator treatments. Weed Research 45: 467-476.

Suh C, Chrysayi-Tokousbalides M, Fokialakis N, Konstantinos A (2014). Influence of growth stimulants and hormones (GR 24 and Nijmegen) on germination of Orobanche and morphology of its calluses. African Advances in Agricultural Research, 1(1):1-10 


\section{Publish Online and Print Version Both}

ISSN Online: 2312-203X 